\title{
Cooking fuel and the risk of pregnancy-induced hypertension in Lanzhou, China: A birth cohort study
}

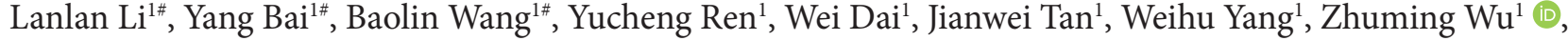 \\ Yaguang $\mathrm{Hu}^{1 \star}$
}

\begin{abstract}
Background: The relationship between the solid fuels and the occurrence of pregnancy-induced hypertension (PIH) is inconclusive. Methods: A birth cohort study of 10,452 pregnant women without chronic hypertension was conducted from 2010 to 2012 at the Gansu Provincial Maternity and Child Care Hospital in Lanzhou, China. Multivariable logistic regression models were used to assess the relationship. Results: Compared to pregnant women using gas as cooking fuel, pregnant women using coal ( $\mathrm{OR}=2.55,95 \% \mathrm{CI}: 1.85-3.51)$ and biomass $(\mathrm{OR}=3.58,95 \% \mathrm{CI}$ : 2.29-5.60) were associated with an increased risk of $\mathrm{PIH}$, gestational hypertension (biomass: $\mathrm{OR}=3.38,95 \% \mathrm{CI}: 1.68-6.80$ ), and preeclampsia (coal: OR=2.89, 95\% CI: 1.98-4.21; biomass: $\mathrm{OR}=3.38,95 \% \mathrm{CI}: 1.95-5.84)$. The relationship between cooking fuel and $\mathrm{PIH}$ is modified by maternal age $(p<0.0001)$, pre-pregnancy BMI $(p<0.0001)$, gestational weigh gain $(p<0.0001)$, parity $(p<0.0001)$, and multiple birth $(p<0.0001)$. Conclusions: During pregnancy, exposure to coal or biomass was associated with an increased risk of PIH and preeclampsia.
\end{abstract}

Keywords: cooking fuel; pregnancy-induced hypertension; preeclampsia; birth cohort; China.

Pratical Application: Exposure to coal or biomass was associated with an increased risk of PIH and preeclampsia during pregnancy.

\section{Introduction}

Solid fuels, such as coal and biomass (wood, crop residues), are widely used for cooking in worldwide, approximately half of the world's population (International Energy Agency \& Organisation for Economic Cooperation and Development, 2004).In China, gas, biomass, solar/electricity, and coal, the main energy fuels for cooking, are used by $44.8 \%, 32.1 \%, 11.7 \%$ and $11.3 \%$ of households, respectively. (Duan et al., 2014) Studies found that indoor $\mathrm{PM}_{2.5}$ concentrations is higher than that in outdoor air due to inefficient combustion of solid fuel, especially in rural areas. (Li et al., 2016; Shen et al., 2010) Indoor air pollution (IAP) is associated with illness and premature deaths and more than 800,000 deaths were caused in 2013 by IAP in China (Institute for Health Metrics and Evaluation, 2016).Cohort studies found that IAP from solid fuels has been proved to be associated with the increases risk of blood pressure,(Baumgartner et al., 2011; Clark et al., 2011) and chronic hypertension (Dutta \& Ray, 2012; Lee et al., 2012) in non-pregnant populations. However, there is a paucity of studies on the correlation between solid fuels and the risk of pregnancy-induced hypertension (PIH).

Hypertension is one of the most common complications during pregnancy, with $10 \%$ of all pregnancies in the population worldwide having hypertension. (Ghulmiyyah \& Sibai, 2012) PIH are classified into 4 categories: 1) preeclampsia-eclampsia, 2 ) chronic hypertension (of any cause), 3) preeclampsia (PE) superimposed on chronic hypertension, 4) gestational hypertension (GH) (American College of Obstetricians and Gynecologists \& Task Force on Hypertension in Pregnancy, 2013). PIH can lead to severe maternal and fetal complications, such as cardiovascular disease, liver and kidney failure, placental abruption, preterm delivery, fetal distress, fetal growth restriction and stillbirth, and also increase lifetime risk of cardiovascular disease of both maternal and their children. (Grandi et al., 2017; Alsnes et al., 2017) Few studies reported the link between cooking fuel and $\mathrm{PIH}$, and the results have been inconsistent.(Wylie et al., 2015; Agrawal \& Yamamoto, 2015) Furthermore, no study has been conducted in a Chinese population, where solid fuels are used as the main energy fuels for cooking. To further investigate the association between cooking fuel and risk of $\mathrm{PIH}$, we conducted a birth cohort study in Lanzhou, China.

For the first time, the associations between types of cooking fuels and the risk of PIH were evaluated in a Chinese population, in which an increased risk of PIH among women who using coal or biomass for cooking compared to use of gas, and the risk varies by PIH subtypes were found.

\section{Methods}

The birth cohort study was conducted on 10,542 pregnant women, aged 18 years or older, with no history of mental illness and gestational ages $\geq 20$ weeks, from 2010 to 2012 at the Gansu Provincial Maternity and Child Care Hospital in Lanzhou, China. (Qiu et al., 2014; Huang et al., 2016; Shao et al., 2017) Upon obtaining written consent, an interview was conducted at the hospital using a standardized and structured questionnaire to collect information on demographic factors, reproductive 
history, medical condition and medication use, lifestyle factors, occupational exposures, and residential history. The majority of the participated women (84\%) were interviewed within 3 days after delivery, while others were interviewed within 2 days before delivery. Information on maternal complications was got from the medical records. The final sample was 10,452 after exclusion of women who delivered still birth $(\mathrm{n}=53)$ and who had chronic hypertension $(n=37)$. All study procedures were approved by the human investigation committees at the Gansu Provincial Maternity and Child Care Hospital and Yale University.

Information regarding cooking fuel used in current and each past residence was collected, including the duration of stay in each residence (date from move in and move out), the type of fuel used for cooking in each residence (gas, electromagnetic, coal, biomass and others), ventilation during cooking, and the most common way of cooking (deep fried, pan fried, braised, steaming, simmer, and other) before and during pregnancy.

PIH cases included GH, PE and eclampsia. GH was defined as hypertension (blood pressure $\geq 140 / 90 \mathrm{mmHg}$ ) and no proteinuria was measured twice at a $6 \mathrm{~h}$ interval after 20 weeks of gestation. $\mathrm{PE}$ was defined as hypertension with proteinuria $(\geq 300 \mathrm{mg}$ per 24 hour) or proteinuria of at least $1+$ on dipstick test after 20 weeks of gestation. PE was further classified as mild PE (M-PE), severe PE (S-PE), early-onset PE (EOPE), and late-onset PE (LOPE). M-PE was diagnosed as hypertension $(\geq 140 / 90 \mathrm{mmHg}$ and $<160 / 110 \mathrm{mmHg}$ ) and proteinuria $(\geq 1+$ and $<2+$ on dipstick test in two urine samples) without serious symptoms. S-PE was diagnosed as hypertension $(\geq 160 / 110 \mathrm{mmHg}$ ) and proteinuria $(\geq 2+$ on dipstick test in two urine samples) with symptoms, such as headache, blurred vision, epigastric burning pain, decreased urine output, decreased or absent fetal kick. EOPE was defined as PE diagnosed before 34 weeks of gestation while LOPE was defined as PE diagnosed after 34 weeks of gestation. Eclampsia was defined as a new onset of seizures association with PE.

Gestational weight gain (GWG) was calculated by subtracting pre-pregnancy weight from the weight at delivery. Pre-pregnancy weight was self-reported. According to the US Institute of Medicine (IOM) GWG Guidelines (Institute of Medicine \& National Research Council, 2009), GWG was categorized into insufficient, sufficient and excessive. Sufficient GWG was divided into underweight, normal weight, overweight, and obese with $12.5-18 \mathrm{~kg}, 11.5-16 \mathrm{~kg}, 7-11.5 \mathrm{~kg}$, and $5-9 \mathrm{~kg}$, respectively.

\subsection{Statistical analysis}

Chi-square tests (or fisher's exact tests if necessary) were used to evaluate the differences in selected characteristics between women with PIH and normotensive and between women using different types of cooking fuel. Multivariate logistic regression models were used to evaluate odds ratios (OR) and $95 \%$ confidence intervals (CI) for the association between cooking fuel and risk of PIH, as well as its clinical subtypes. Potential confounding factors included maternal age $(<25,25-29,30-34$, and $\geq 35)$, education ( $<$ College, $\geq$ College), monthly income $(<2000, \geq 2000)$, maternal employment during pregnancy (yes or no), parity (primipara or multipara), pre-pregnancy BMI $(<18.5,18.5-23.9$, $\geq 24$ ), GWG (insufficient, sufficient, and excessive), smoking during pregnancy (yes or no), folate intake during pregnancy (yes or no), multiple births (yes or no), and ventilation (yes or no) were analyzed. Additional adjustments, such as history of $\mathrm{PIH}$, family history of PIH, maternal diabetes, maternal renal disease before pregnancy and progeny gender, didn't result in maternal changes observed in pregnant women and were not included in the final models. All analyses were performed using SAS, version 9.4(SAS Institute Inc., Cary, NC, USA).

\section{Results}

\subsection{Pregnant women with PIH showed different characteristic compared with normotensive pregnant women}

568(5.43\%) were diagnosed with PIH, in which 180 cases (31.69\%) were GH, 377 (66.37\%) were PE, and 11(1.94\%) were eclampsia. Among those PE cases, 148 (39.26\%) were M-PE, 229(60.74\%) were S-PE. Compared to normotensive women, women with PIH were more likely to be older, less educated, less family income, higher unemployment during pregnancy, multipara, higher pre-pregnancy BMI and GWG, and have history of PIH, family history of $\mathrm{PIH}$, maternal diabetes, maternal renal disease before pregnancy, less folate intake during pregnancy, multiple births, and poor cooking ventilation (Table 1). There were no significant differences in exposure to smoking during pregnancy and progeny gender between women with and without PIH.

\subsection{Pregnant women using different type of cooking fuel showed different characteristic}

8182(78.28\%) only used gas as cooking fuel, 197(1.88\%) only used electromagnetic stoves, 506 (4.84\%) only used coal, and $173(1.66 \%)$ only used biomass (Table 2). The remaining 1394 pregnant women used other fuel or multiple stoves as their cooking fuel. Compared to women who used gas, women who used coal, biomass, or electromagnetic stoves were younger, less educated, less family monthly income, unemployment during pregnancy, multipara, insufficient GWG, less normal BMI, less folate intake during pregnancy, exposuring to smoking during pregnancy, multiple births, and poor cooking ventilation.

\subsection{Using coal or biomass as cooking fuel was associated increased risk of PIH and PE for pregnant women}

Compared to using gas for cooking, using coal ( $\mathrm{OR}=2.55$, 95\% CI: $1.85-3.51$ ) or biomass (OR=3.58, 95\% CI: 2.29-5.60) was associated with the increased risk of PIH. Using biomass was associated with the increased risk of $\mathrm{GH}(\mathrm{OR}=3.38,95 \%$ CI: 1.68 6.80) and preeclampsia-eclampsia ( $\mathrm{OR}=3.64,95 \% \mathrm{CI}: 2.14-6.19$ ). Using coal was associated with the increased risk of Preeclampsiaeclampsia (OR=2.98, 95\% CI: 2.06-4.31). No significant correlation were observed for electromagnetic stoves (Table 3 ).

Using coal (OR=2.89, 95\% CI: $1.98-4.21)$ or biomass $(\mathrm{OR}=3.38,95 \% \mathrm{CI}: 1.95-5.84)$ were associated with higher risk of PE. Using biomass was associated with an increased risk of M-PE (OR=2.94, 95\% CI: 1.13-7.63) and S-PE (OR=3.46, 95\% CI: 1.83-6.52).Using coal was associated with an increased risk of 
Table 1. Distribution of selected characteristics of the study population.

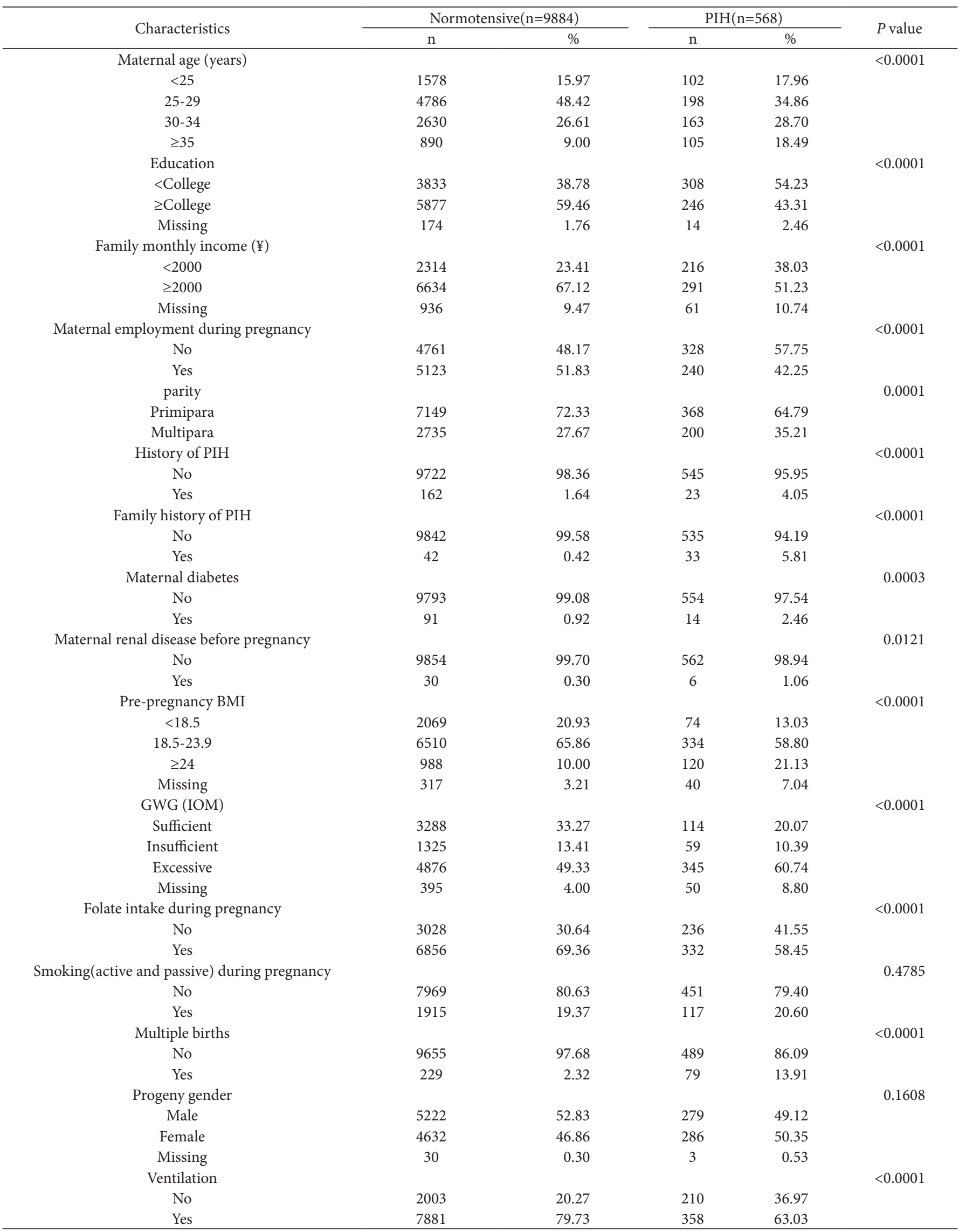

Abbreviations: BMI (body mass index), GWG (gestational weight gain), IOM (Institute of Medicine), PIH (pregnancy-induced hypertension). 
Original Article

Cooking fuel and the risk of PIH

Table 2. Distribution of selected characteristics of the study population by cooking fuel types.

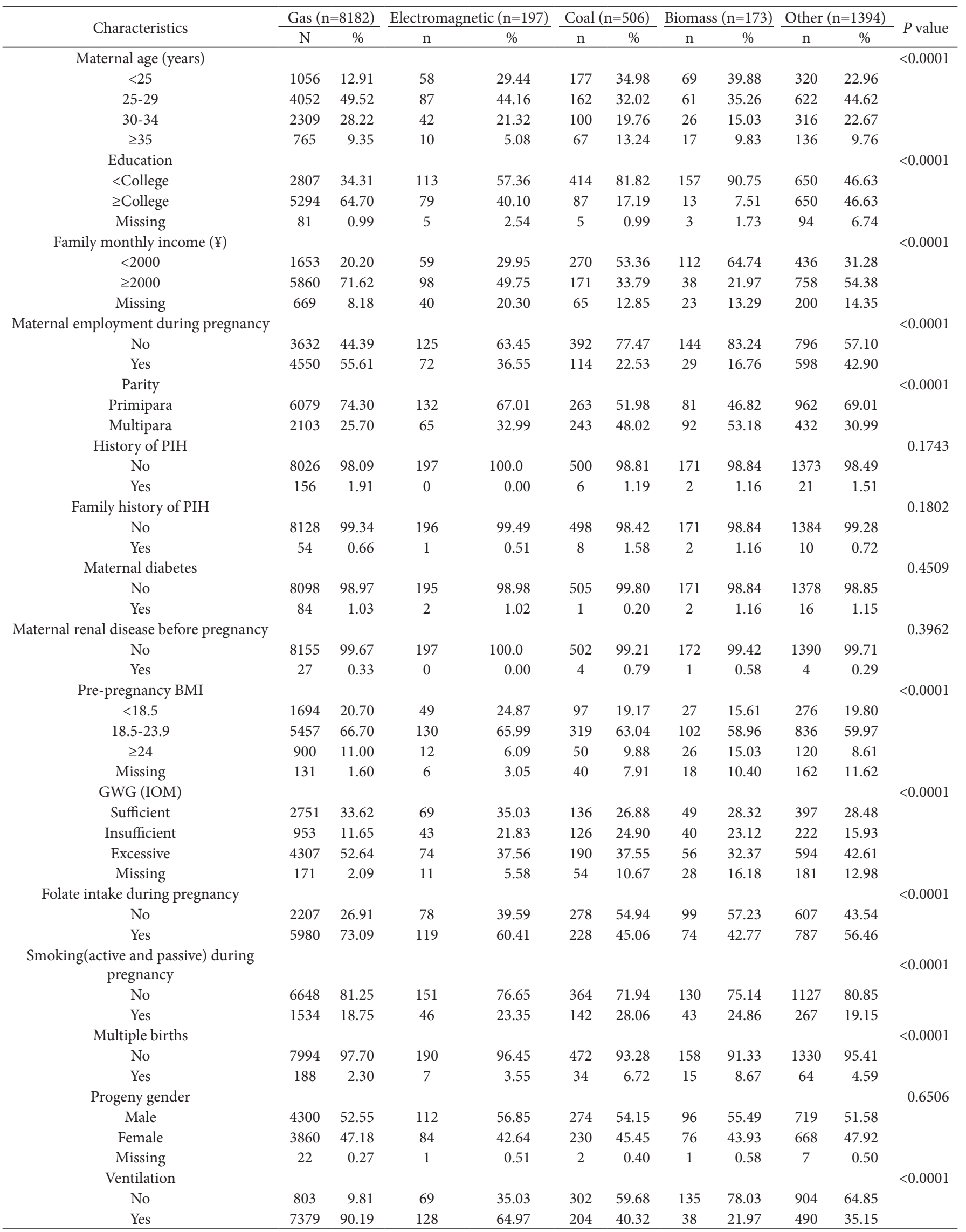

Abbreviations: BMI, body mass index; GWG, gestational weight gain; IOM, Institute of Medicine; PIH, pregnancy-induced hypertension. 
Table 3. Associations of cooking fuel types with risk of PIH.

\begin{tabular}{|c|c|c|c|c|c|c|c|}
\hline \multirow{2}{*}{ Cooking fuel types } & \multirow{2}{*}{ Term (n) } & \multicolumn{2}{|r|}{$\mathrm{PIH}(\mathrm{n}=568)$} & \multicolumn{2}{|r|}{$\mathrm{GH}(\mathrm{n}=180)$} & \multicolumn{2}{|c|}{ (Pre)-eclampsia $(\mathrm{n}=388)$} \\
\hline & & No. & $\mathrm{OR}(95 \% \mathrm{CI})$ & No. & $\mathrm{OR}(95 \% \mathrm{CI})$ & No. & $\mathrm{OR}(95 \% \mathrm{CI})$ \\
\hline Gas & 7837 & 345 & 1.00 (ref) & 117 & 1.00 (ref) & 228 & 1.00 (ref) \\
\hline Electromagnetic & 187 & 10 & $1.24(0.64-2.41)$ & 5 & $1.71(0.68-4.30)$ & 5 & $0.98(0.39-2.44)$ \\
\hline Coal & 433 & 73 & $2.55(1.85-3.51)$ & 17 & $1.71(0.95-3.06)$ & 56 & $2.98(2.06-4.31)$ \\
\hline Biomass & 137 & 36 & $3.58(2.29-5.60)$ & 12 & $3.38(1.68-6.80)$ & 24 & $3.64(2.14-6.19)$ \\
\hline
\end{tabular}

Note: adjusted for maternal age, education, monthly income, maternal employment during pregnancy, parity, BMI, GWG, smoking (active and passive smoking), folate intake during pregnancy, multiple births, and ventilation.

S-PE (OR=3.23, 95\% CI: 2.06-5.06). No significant correlations were also observed for electromagnetic stoves (Table 4).

\subsection{Using coal or biomass as cooking fuel was associated increased risk of PIH in different groups of pregnant women}

In this study, whether maternal age, pre-pregnancy BMI, GWG, parity, and multiple births were effect modifiers was been analyzed (Table 5). Statistically significant interactions were observed between cooking fuel and maternal age (Interaction $P<0.0001$ ), pre-pregnancy BMI (Interaction $P<0.0001$ ), GWG (Interaction $P<0.0001$ ), parity (Interaction $P<0.0001$ ), and multiple births (Interaction $P<0.0001$ ). Among women who were younger than 30 , compared to using gas for cooking, using coal $(<30, \mathrm{OR}=3.09,95 \% \mathrm{CI}: 1.94-4.93 ; \geq 30, \mathrm{OR}=2.10$, $95 \%$ CI: 1.04-4.26), and biomass ( $<30, \mathrm{OR}=4.73,95 \%$ CI: 2.62 8.52 ) were significantly associated with the risk of PIH. Among women who with normal pre-pregnancy BMI, compared to

Table 4. Associations of cooking fuel types with risk of preeclampsia.

\begin{tabular}{|c|c|c|c|c|c|c|c|}
\hline \multirow{2}{*}{ Cooking fuel types } & \multirow{2}{*}{ Term (n) } & \multicolumn{2}{|r|}{$\mathrm{PE}(\mathrm{n}=377)$} & \multicolumn{2}{|r|}{ M-PE $(n=148)$} & \multicolumn{2}{|r|}{ S-PE $(n=229)$} \\
\hline & & No. & $\mathrm{OR}(95 \% \mathrm{CI})$ & No. & $\mathrm{OR}(95 \% \mathrm{CI})$ & No. & $\mathrm{OR}(95 \% \mathrm{CI}$ \\
\hline Gas & 7837 & 224 & 1.00 (ref) & 99 & 1.00 (ref) & 125 & 1.00 (ref) \\
\hline Electromagnetic & 187 & 5 & $1.00(0.40-2.50)$ & 2 & $1.02(0.24-4.29)$ & 3 & $1.01(0.31-3.28)$ \\
\hline Coal & 433 & 53 & $2.89(1.98-4.21)$ & 14 & $2.21(1.17-4.17)$ & 39 & $3.23(2.06-5.06)$ \\
\hline Biomass & 137 & 22 & $3.38(1.95-5.84)$ & 6 & $2.94(1.13-7.63)$ & 16 & $3.46(1.83-6.52)$ \\
\hline
\end{tabular}

Note: adjusted for maternal age, education, monthly income, maternal employment during pregnancy, parity, BMI, GWG, smoking (active and passive smoking), folate intake during pregnancy, multiple births, and ventilation.

Table 5. Associations between cooking fuel types and risk of PIH by maternal age, pre-pregnancy, gestational weight gain, parity, and multiple births.

\begin{tabular}{|c|c|c|c|c|c|c|c|c|c|}
\hline \multirow{3}{*}{ Characteristics } & \multicolumn{3}{|c|}{ Gas } & \multicolumn{3}{|c|}{ Coal } & \multicolumn{3}{|c|}{ Biomass } \\
\hline & \multirow{2}{*}{ Term (n) } & \multicolumn{2}{|r|}{$\mathrm{PIH}$} & \multirow{2}{*}{ Term (n) } & \multicolumn{2}{|r|}{$\mathrm{PIH}$} & \multirow{2}{*}{ Term (n) } & \multicolumn{2}{|r|}{$\mathrm{PIH}$} \\
\hline & & No. & OR(95\% CI) & & No. & OR(95\% CI) & & No. & OR(95\% CI) \\
\hline \multicolumn{10}{|l|}{ Maternal age } \\
\hline$<30$ & 4999 & 109 & 1.00 (ref) & 307 & 32 & $3.09(1.94-4.93)$ & 110 & 20 & $4.73(2.62-8.52)$ \\
\hline$\geq 30$ & 2955 & 119 & $0.78(0.45-1.34)$ & 143 & 24 & $2.10(1.04-4.26)$ & 39 & 4 & $0.93(0.27-3.11)$ \\
\hline Interaction $P$ value & & & & & & & & & $<0.0001$ \\
\hline \multicolumn{10}{|l|}{ Pre-pregnancy BMI } \\
\hline $18.5-23.9$ & 5320 & 127 & $1.00(\mathrm{ref})$ & 286 & 33 & $3.16(2.01-4.95)$ & 89 & 13 & $3.31(1.67-6.57)$ \\
\hline$<18.5$ & 1665 & 29 & $1.23(0.53-2.86)$ & 91 & 6 & $3.05(0.96-9.70)$ & 24 & 3 & $3.92(0.83-18.42)$ \\
\hline$\geq 24$ & 842 & 58 & $1.40(0.65-3.00)$ & 39 & 11 & $3.22(1.14-9.04)$ & 21 & 5 & $4.11(1.17-14.42)$ \\
\hline Interaction $P$ value & & & & & & & & & $<0.0001$ \\
\hline \multicolumn{10}{|l|}{ GWG } \\
\hline sufficient & 2713 & 38 & $1.00(\mathrm{ref})$ & 131 & 5 & $1.09(0.40-3.00)$ & 47 & 2 & $1.66(0.37-7.39)$ \\
\hline insufficient & 936 & 17 & $1.89(0.62-5.76)$ & 116 & 10 & $6.02(1.78-20.35)$ & 37 & 3 & $4.88(1.01-23.58)$ \\
\hline excessive & 4140 & 167 & $1.47(0.74-2.91)$ & 156 & 34 & $5.27(2.39-11.61)$ & 45 & 11 & $3.71(1.37-10.04)$ \\
\hline Interaction $P$ value & & & & & & & & & $<0.0001$ \\
\hline \multicolumn{10}{|l|}{ Parity } \\
\hline primipara & 5920 & 159 & $1.00(\mathrm{ref})$ & 234 & 29 & $3.20(1.99-5.16)$ & 66 & 15 & $5.19(2.64-10.22)$ \\
\hline multipara & 2034 & 69 & $0.80(0.46-1.39)$ & 216 & 27 & $2.14(1.09-4.22)$ & 83 & 9 & $1.63(0.66-4.01)$ \\
\hline Interaction $P$ value & & & & & & & & & $<0.0001$ \\
\hline \multicolumn{10}{|l|}{ Multiple births } \\
\hline No & 7800 & 194 & $1.00(\mathrm{ref})$ & 424 & 48 & $3.43(2.35-5.02)$ & 138 & 20 & $3.97(2.28-6.90)$ \\
\hline Yes & 154 & 34 & $0.95(0.45-2.03)$ & 26 & 8 & $1.01(0.35-2.93)$ & 11 & 4 & $1.19(0.31-4.62)$ \\
\hline Interaction $P$ value & & & & & & & & & $<0.0001$ \\
\hline
\end{tabular}

Note: Adjusted for maternal age, education, monthly income, maternal employment during pregnancy, parity, BMI, GWG, smoking (active and passive smoking), folate intake during pregnancy, multiple births, and ventilation. 
using gas for cooking, using coal (normal, OR=3.16, 95\% CI: 2.01-4.95; overweight, $\mathrm{OR}=3.22$, 95\% CI: 1.14-9.04), and biomass (normal, $\mathrm{OR}=3.31,95 \% \mathrm{CI}$ : 1.67-6.57; overweight, $\mathrm{OR}=4.11$, 95\% CI: 1.17-14.42) were also significantly associated with the risk of PIH. Also, increased risk of PIH was associated with using coal among women who had less $(\mathrm{OR}=6.02,95 \% \mathrm{CI}$ : 1.78-20.35) or more GWG (OR=5.27, 95\% CI: 2.39-11.61), as well as insufficient ( $\mathrm{OR}=4.88,95 \% \mathrm{CI}$ : 1.01-23.58) or excessive biomass (OR=3.71, 95\% CI: 1.37-10.04). Using coal or biomass 1 was significantly associated with the risk of PIH for primipara (coal, OR=3.20, 95\% CI: 1.99-5.16; biomass, OR=5.19, 95\% CI: 2.64-10.22) and single birth (coal, OR=3.43, 95\% CI: 2.35-5.02; biomass, $\mathrm{OR}=3.97,95 \% \mathrm{CI}$ : 2.28-6.90).

\section{Discussion}

A few studies have estimated the association between types of cooking fuels and the risk of PIH, and the results were inconsistent.(Wylie et al., 2015; Agrawal \& Yamamoto, 2015) In India, Wylie et al. (2015) conduct a study including 1369 (212 hypertension at delivery) subjects and found that compared to women cooking with gas, $14.6 \%$ of women using wood and $19.6 \%$ women using gas as their primary fuel met criteria for hypertension at delivery $(\mathrm{P}=0.057)$, but using wood fuel was not significantly associated with hypertension (adjusted prevalence ratio $0.76[95 \%$ CI $0.49,1.17])$. They speculate that this effect may be related to the combustion by-products of biomass fuels, which are quite similar to tobacco and cigarette smoking during pregnancy was associated with a significantly reduced risk for PE (OR $=0.51,95 \%$ CI: 0.37-0.63) have been reported in metaanalysis.(Castles et al., 1999) Agrawal S et al(2015) conducted a large-scale cross-sectional nationally representative of adult women in India including 39,657 women (456 preeclampsia/ eclampsia), and suggested that women living in households using biomass and solid fuels were associated with an increased risk of preeclampsia/eclampsia symptoms compared to women living in households using cleaner fuels $(\mathrm{OR}=2.21,95 \% \mathrm{CI}$ : 1.26 3.87 ), even after controlling potentially confounding factors. Consistent with the study, we also observed that using coal or biomass was associated with significantly increased risk of PE. This study suggested that biomass and coal exposure were associated with S-PE, biomass exposure also was associated with M-PE. While no study evaluated M-PE and S-PE separately in relation to solid fuels. We found that maternal age, pre-pregnancy BMI, GWG, parity, and multiple births modified the association between cooking fuels and risk of PIH. Studies reported that pre-pregnancy BMI and GWG were significantly associated with the risk of PIH (Shao et al., 2017; Stüber et al., 2015).

The combustion byproducts of solid fuel are a complex mixture of particulate and gaseous species such as particulate matter (PM), polycyclic aromatic hydrocarbons, heavy metals, carbon monoxide (CO), nitrogen dioxide $\left(\mathrm{NO}_{2}\right)$, sulfur dioxide $\left(\mathrm{SO}_{2}\right)$, ozone $\left(\mathrm{O}_{3}\right)$ and so on. (Zhang \& Smith, 2007) Previous studies have suggested that particulate exposure was associated with PIH (Zhu et al., 2017; Savitz et al., 2015; Lee et al., 2013; Huang et al., 2015) but inconsistent. A large retrospective cohort study from 2008 to 2010 in United States, including 206,054 women with $6074 \mathrm{GH}$, found that exposure to $\mathrm{NO}_{\mathrm{x}}, \mathrm{PM}_{2.5}$, and
$\mathrm{SO} 2$ during the first trimester, and $\mathrm{NO}_{\mathrm{x}}, \mathrm{PM}_{2.5}, \mathrm{PM}_{10}$, and $\mathrm{SO}_{2}$ during gestational weeks 1-20 were associated with higher risk of GH. (Zhu et al., 2017) However, Savitz et al. (2015) conducted a study in New York City involving 268,601 women (PE 11,166, $\mathrm{GH} 5,834$ and 17,000 PIH) and suggested a lack of evidence of a positive association between $\mathrm{PM}_{2.5}$ or $\mathrm{NO}_{2}$ and $\mathrm{PIH}$. Lee et al. (2013) reported $\mathrm{PM}_{2.5}$ exposure (per IQR increase) during first trimester was associated with $\mathrm{GH}(\mathrm{OR}=1.11,95 \% \mathrm{CI}$ : 1.00-1.23) but not for $\mathrm{PM}_{10}$ in Pittsburgh, Pennsylvania. Whereas Jin L et al (Huang et al., 2015) conducted a cohort study in China that included 8745 women (333 PIH, $127 \mathrm{GH}$ and $206 \mathrm{PE})$ and observed a $10 \%$ increase for the risk of $\mathrm{GH}(\mathrm{OR}=1.10,95 \%$ CI: $1.00,1.21)$ during the first 12 gestational weeks after $\mathrm{PM}_{10}$ exposure (per $10 \mu \mathrm{g} / \mathrm{m}^{-3}$ increase) and S-PE during the first 20 gestational weeks was associated with $\mathrm{PM}_{10}(\mathrm{OR}=1.14,95 \%$ CI: $1.01,1.30$ per $10 \mu \mathrm{g} / \mathrm{m}^{-3}$ increase). Pedersen et al. (2017) in Denmark conduct a study including 72,745(PE 1880 and PIH 2430) pregnancies study subjects and found that a $10-\mu \mathrm{g} / \mathrm{m}^{3}$ increase in $\mathrm{NO}_{2}$ exposure during first trimester was associated with increased risk of $\mathrm{PE}(\mathrm{OR}=1.07,95 \% \mathrm{CI}$ : 1.01-1.14) and $\mathrm{PIH}$ $(\mathrm{OR}=1.07,95 \% \mathrm{CI}: 1.01-1.13)$. A random-effect meta-analysis of ambient air pollution and pregnancy-induced hypertensive disorders also suggested that a $10 \mu \mathrm{g} / \mathrm{m}^{3}$ increase in $\mathrm{NO}_{2}$ was associated with $\mathrm{PIH}(\mathrm{OR}=1.23$, 95\% CI: 1.04-1.41).(Pedersen et al., 2014) Hampel et al. (2011) found negative short-term $\mathrm{NO}_{2}$ effects on systolic blood pressure in pregnant women. A nationwide time -series analysis in China reported a short-term increase in ambient $\mathrm{SO}_{2}$ concentration may induce deaths from hypertension disease (Wang et al., 2018).

The exact mechanisms of IAP exposure from solid fuels on $\mathrm{PIH}$ occurrence are not well understood. The basic pathological and physiological changes of PIH are systemic small blood vessels spasm, endothelial injury and ischemia. PM exposure is associated with systemic inflammation, endothelial dysfunction, and oxidative stress.(Becker et al., 2005; Bind et al., 2012; Ghio et al., 2000; Huang et al., 2012) PM inhalation induces inflammatory responses mediated in the lung and systemically through toll-like receptor 4/nicotinamide adenine dinucleotide phosphate (TLR4/NADPH) oxidase-dependent mechanisms, which promotes endothelial dysfunction. (Kampfrath et al., 2011) Pulmonary exposure to PM leads to activation of lung autonomic nervous system (ANS) arcs mediated, then cause ANS imbalance, leading to vasoconstriction, endothelial dysfunction, hypertension.(Chin, 2015) Routledge et al. (2006) found that $\mathrm{SO}_{2}$ exposure can induce oxidative stress, and elevate markers of inflammation.

There were several limitations in the present study. The information on household heating source was not obtained in our study. The type of fuels of household heating was relevant to family income and education, therefore we adjusted the potential confounding in our models. The large participants of our study were came from urban areas where was concentrated heating. Whether participants in our study were the primary person in charge of food preparation, time spent in kitchen, number of meals cooked per day, and time for indoor activities were not collected in the study, which might result in exposure misclassification. However, the exposure misclassification would likely be negligible. Lack of indoor air pollution monitoring 
restricted us to explore the association between the amount of air pollution and the risk of PIH.

\section{Conclusions}

The cohort study in Chinese population suggested that exposure to coal or biomass during pregnancy was associated with an increased risk of PIH, PE and S-PE. Biomass was also associated with an increased risk of GH and M-PE. Future studies were warranted to confirm the associations in different populations and clarify the biological mechanisms.

\section{References}

American College of Obstetricians and Gynecologists, \& Task Force on Hypertension in Pregnancy. (2013). Hypertension in pregnancy. Report of the American College of Obstetricians and Gynecologists' task force on hypertension in pregnancy. Obstetrics and Gynecology, 122(5), 1122-1131. PMid:24150027.

Alsnes, I. V., Vatten, L. J., Fraser, A., Bjørngaard, J. H., Rich-Edwards, J., Romundstad, P. R., \& Åsvold, B. O. (2017). Hypertension in pregnancy and offspring cardiovascular risk in young adulthood: prospective and sibling studies in the HUNT Study (Nord-Trøndelag Health Study) in Norway. Hypertension, 69(4), 591-598.

Agrawal, S., \& Yamamoto, S. (2015). Effect of indoor air pollution from biomass and solid fuel combustion on symptoms of preeclampsia/ eclampsia in Indian women. Indoor Air, 25(3), 341-352. http:// dx.doi.org/10.1111/ina.12144. PMid:25039812.

Baumgartner, J., Schauer, J. J., Ezzati, M., Lu, L., Cheng, C., Patz, J. A., \& Bautista, L. E. (2011). Indoor air pollution and blood pressure in adult women living in rural China. Environmental Health Perspectives, 119(10), 1390-1395. http://dx.doi.org/10.1289/ehp.1003371. PMid:21724522.

Becker, S., Dailey, L. A., Soukup, J. M., Grambow, S. C., Devlin, R. B., \& Huang, Y. C. (2005). Seasonal variations in air pollution particle-induced inflammatory mediator release and oxidative stress. Environmental Health Perspectives, 113(8), 1032-1038. http://dx.doi. org/10.1289/ehp.7996. PMid:16079075.

Bind, M. A., Baccarelli, A., Zanobetti, A., Tarantini, L., Suh, H., Vokonas, P., \& Schwartz, J. (2012). Air pollution and markers of coagulation, inflammation, and endothelial function: associations and epigeneenvironment interactions in an elderly cohort. Epidemiology, 23(2), 332-340. http://dx.doi.org/10.1097/EDE.0b013e31824523f0. PMid:22237295.

Castles, A., Adams, E. K., Melvin, C. L., Kelsch, C., \& Boulton, M. L. (1999). Effects of smoking during pregnancy. Five meta-analyses. American Journal of Preventive Medicine, 16(3), 208-215. http:// dx.doi.org/10.1016/S0749-3797(98)00089-0. PMid:10198660.

Chin, M. T. (2015). Basic mechanisms for adverse cardiovascular events associated with air pollution. Heart (British Cardiac Society), 101(4), 253-256. http://dx.doi.org/10.1136/heartjnl-2014-306379. PMid:25552258.

Clark, M. L., Bazemore, H., Reynolds, S. J., Heiderscheidt, J. M., Conway, S., Bachand, A. M., Volckens, J., \& Peel, J. L. (2011). A baseline evaluation of traditional cook stove smoke exposures and indicators of cardiovascular and respiratory health among Nicaraguan women. International Journal of Occupational and Environmental Health, 17(2), 113-121. http://dx.doi. org/10.1179/107735211799030942. PMid:21618943.

Duan, X., Jiang, Y., Wang, B., Zhao, X., Shen, G., Cao, S., Huang, N., Qian, Y., Chen, Y., \& Wang, L. (2014). Household fuel use for cooking and heating in China: Results from the first Chinese Environmental
Exposure-Related Human Activity Patterns Survey (CEERHAPS). Applied Energy, 136, 692-703. http://dx.doi.org/10.1016/j.apenergy.2014.09.066.

Dutta, A., \& Ray, M. R. (2012). Prevalence of hypertension and prehypertension in rural women: a report from the villages of West Bengal, a state in the eastern part of India. The Australian Journal of Rural Health, 20(4), 219-225. http://dx.doi.org/10.1111/j.14401584.2012.01287.x. PMid:22827431.

Ghulmiyyah, L., \& Sibai, B. (2012). Maternal mortality from preeclampsia/ eclampsia. Seminars in Perinatology, 36(1), 56-59. http://dx.doi. org/10.1053/j.semperi.2011.09.011. PMid:22280867.

Grandi, S. M., Vallée-Pouliot, K., Reynier, P., Eberg, M., Platt, R. W., Arel, R., Basso, O., \& Filion, K. B. (2017). Hypertensive disorders in pregnancy and the risk of subsequent cardiovascular disease. Paediatric and Perinatal Epidemiology, 31(5), 412-421. http://dx.doi. org/10.1111/ppe.12388. PMid:28816365.

Ghio, A. J., Kim, C., \& Devlin, R. B. (2000). Concentrated ambient air particles induce mild pulmonary inflammation in healthy human volunteers. American Journal of Respiratory and Critical Care Medicine, 162(3 Pt 1), 981-988. http://dx.doi.org/10.1164/ ajrccm.162.3.9911115. PMid:10988117.

Huang, W., Wang, G., Lu, S. E., Kipen, H., Wang, Y., Hu, M., Lin, W., Rich, D., Ohman-Strickland, P., Diehl, S. R., Zhu, P., Tong, J., Gong, J., Zhu, T., \& Zhang, J. (2012). Inflammatory and oxidative stress responses of healthy young adults to changes in air quality during the Beijing Olympics. American Journal of Respiratory and Critical Care Medicine, 186(11), 1150-1159. http://dx.doi.org/10.1164/ rccm.201205-0850OC. PMid:22936356.

Huang, X., Qiu, J., Zhang, Y., Qiu, W., He, X., Wang, Y., Sun, Q., Zhao, N., Cui, H., Liu, S., Tang, Z., Chen, Y., Yue, L., Da, Z., Lv, L., Lin, X., Zhang, C., Zhang, H., Xu, R., Zhu, D., Xu, X., Lin, R., Yao, T., Su, J., Dang, Y., Han, X., Zhang, H., Bai, H., Wang, W., Wang, Y., Liu, X., Ma, B., Huang, H., Liang, J., Jiang, M., Ma, S., \& Michelle, L. (2015). Ambient air pollutant PM10 and risk of pregnancy-induced hypertension in urban China. Environmental Research Letters, 10(8), 084025. http://dx.doi.org/10.1088/1748-9326/10/8/084025.

Huang, L., Lerro, C., Yang, T., Li, J., Qiu, J., Qiu, W., He, X., Cui, H., Lv, L., Xu, R., Xu, X., Huang, H., Liu, Q., \& Zhang, Y. (2016). Maternal tea consumption and the risk of preterm delivery in urban China: a birth cohort study. BMC Public Health, 16(1), 456. http://dx.doi. org/10.1186/s12889-016-3100-3. PMid:27246202.

Hampel, R., Lepeule, J., Schneider, A., Bottagisi, S., Charles, M. A., Ducimetière, P., Peters, A., \& Slama, R. (2011). Short-term impact of ambient air pollution and air temperature on blood pressure among pregnant women. Epidemiology, 22(5), 671-679. http://dx.doi. org/10.1097/EDE.0b013e318226e8d6. PMid:21730862.

Institute for Health Metrics and Evaluation. (2016). Global burden of disease study 2013. Retrieved from http://www.healthdata.org/gbd

Institute of Medicine - IOM \& National Research Council - NRC. (2009) Weight gain during pregnancy: Reexamining the guidelines. Washington, DC: The National Academies Press.

International Energy Agency - IEA \& Organisation for Economic Cooperation and Development - OECD. (2004). World Energy Outlook 2004. Paris: International Energy Agency and Organisation for Economic Co-operation and Development.

Kampfrath, T., Maiseyeu, A., Ying, Z., Shah, Z., Deiuliis, J. A., Xu, X., Kherada, N., Brook, R. D., Reddy, K. M., Padture, N. P., Parthasarathy, S., Chen, L. C., Moffatt-Bruce, S., Sun, Q., Morawietz, H., \& Rajagopalan, S. (2011). Chronic fine particulate matter exposure induces systemic vascular dysfunction via NADPH oxidase and TLR4 pathways. Circulation Research, 108(6), 716-726. http://dx.doi. org/10.1161/CIRCRESAHA.110.237560. PMid:21273555. 
Lee, M. S., Hang, J. Q., Zhang, F. Y., Dai, H. L., Su, L., \& Christiani, D. C. (2012). In-home solid fuel use and cardiovascular disease: a cross-sectional analysis of the Shanghai Putuo study. Environmental Health, 11(18)

Li, T., Cao, S., Fan, D., Zhang, Y., Wang, B., Zhao, X., Leaderer, B. P., Shen, G., Zhang, Y., \& Duan, X. (2016). Household concentrations and personal exposure of PM2.5 among urban residents using different cooking fuels. The Science of the Total Environment, 548-549, 6-12. http://dx.doi.org/10.1016/j.scitotenv.2016.01.038. PMid:26799802.

Lee, P. C., Roberts, J. M., Catov, J. M., Talbott, E. O., \& Ritz, B. (2013). First trimester exposure to ambient air pollution, pregnancy complications and adverse birth outcomes in Allegheny County, PA. Maternal and Child Health Journal, 17(3), 545-555. http://dx.doi. org/10.1007/s10995-012-1028-5. PMid:22544506.

Pedersen, M., Halldorsson, T. I., Olsen, S. F., Hjortebjerg, D., Ketzel, M., Grandström, C., Raaschou-Nielsen, O., \& Sørensen, M. (2017). Impact of Road Traffic Pollution on Pre-eclampsia and Pregnancy-induced Hypertensive Disorders. Epidemiology, 28(1), 99-106. http://dx.doi.org/10.1097/EDE.0000000000000555. PMid:27648591.

Pedersen, M., Stayner, L., Slama, R., Sørensen, M., Figueras, F., Nieuwenhuijsen, M. J., Raaschou-Nielsen, O., \& Dadvand, P. (2014). Ambient air pollution and pregnancy-induced hypertensive disorders: a systematic review and meta-analysis. Hypertension, 64(3), 494-500.

Qiu, J., He, X., Cui, H., Zhang, C., Zhang, H., Dang, Y., Han, X., Chen, Y., Tang, Z., Zhang, H., Bai, H., Xu, R., Zhu, D., Lin, X., Lv, L., Xu, X., Lin, R., Yao, T., Su, J., Liu, X., Wang, W., Wang, Y., Ma, B., Liu, S., Huang, H., Lerro, C., Zhao, N., Liang, J., Ma, S., Ehrenkranz, R. A., Liu, Q., \& Zhang, Y. (2014). Passive smoking and preterm birth in urban China. American Journal of Epidemiology, 180(1), 94-102. http://dx.doi.org/10.1093/aje/kwu092. PMid:24838804.

Routledge, H. C., Manney, S., Harrison, R. M., Ayres, J. G., \& Townend, J. N. (2006). Effect of inhaled sulphur dioxide and carbon particles on heart rate variability and markers of inflammation and coagulation in human subjects. Heart (British Cardiac Society), 92(2), 220-227. http://dx.doi.org/10.1136/hrt.2004.051672. PMid:15923279.

Savitz, D. A., Elston, B., Bobb, J. F., Clougherty, J. E., Dominici, F., Ito, K., Johnson, S., McAlexander, T., Ross, Z., Shmool, J. L., Matte, T.
D., \& Wellenius, G. A. (2015). Ambient Fine Particulate Matter, Nitrogen Dioxide, and Hypertensive Disorders of Pregnancy in New York City. Epidemiology (Cambridge, Mass.), 26(5), 748-757. http://dx.doi.org/10.1097/EDE.0000000000000349. PMid:26237745.

Shen, G., Yang, Y., Wang, W., Tao, S., Zhu, C., Min, Y., Xue, M., Ding, J., Wang, B., Wang, R., Shen, H., Li, W., Wang, X., \& Russell, A. G. (2010). Emission factors of particulate matter and elemental carbon for crop residues and coals burned in typical household stoves in China. Environmental Science \& Technology, 44(18), 7157-7162. http://dx.doi.org/10.1021/es101313y. PMid:20735038.

Shao, Y., Qiu, J., Huang, H., Mao, B., Dai, W., He, X., Cui, H., Lin, X., Lv, L., Wang, D., Tang, Z., Xu, S., Zhao, N., Zhou, M., Xu, X., Qiu, W., Liu, Q., \& Zhang, Y. (2017). Pre-pregnancy BMI, gestational weight gain and risk of preeclampsia: a birth cohort study in Lanzhou, China. BMC Pregnancy and Childbirth, 17(1), 400. http://dx.doi. org/10.1186/s12884-017-1567-2. PMid:29191156.

Stüber, T. N., Künzel, E. C., Zollner, U., Rehn, M., Wöckel, A., \& Hönig, A. (2015). Prevalence and associated risk factors for obesity during pregnancy over time. Geburtshilfe und Frauenheilkunde, 75(9), 923928. http://dx.doi.org/10.1055/s-0035-1557868. PMid:26500368.

Wylie, B. J., Singh, M. P., Coull, B. A., Quinn, A., Yeboah-Antwi, K., Sabin, L., Hamer, D. H., Singh, N., \& MacLeod, W. B. (2015). Association between wood cooking fuel and maternal hypertension at delivery in central East India. Hypertension in Pregnancy, 34(3), 355-368. http://dx.doi.org/10.3109/10641955.2015.1046604. PMid:26153626.

Wang, L., Liu, C., Meng, X., Niu, Y., Lin, Z., Liu, Y., Liu, J., Qi, J., You, J., Tse, L. A., Chen, J., Zhou, M., Chen, R., Yin, P., \& Kan, H. (2018). Associations between short-term exposure to ambient sulfur dioxide and increased cause-specific mortality in 272 Chinese cities. Environment International, 117, 33-39. http://dx.doi.org/10.1016/j. envint.2018.04.019. PMid:29715611.

Zhang, J. J., \& Smith, K. R. (2007). Household air pollution from coal and biomass fuels in China: measurements, health impacts, and interventions. Environmental Health Perspectives, 115(6), 848-855. http://dx.doi.org/10.1289/ehp.9479. PMid:17589590.

Zhu, Y., Zhang, C., Liu, D., Ha, S., Kim, S. S., Pollack, A., \& Mendola, P. (2017). Ambient Air Pollution and Risk of Gestational Hypertension. American Journal of Epidemiology, 186(3), 334-343. http://dx.doi. org/10.1093/aje/kwx097. PMid:28472208. 